Australasian Journal of

Educational Technology

Volume 20, Number 2, Winter 2004

ISSN $1449-3098$

\title{
Contents
}

Editorial: AJET Author Survey

Technology, human agency and Dewey's constructivism: Opening

democratic spaces in virtual classrooms

Emery J. Hyslop-Margison

Secondary school reform and technology planning: Lessons

learned from a ten year school reform initiative

Alan Bain

Cooperative learning on the web: A group based, student centred

learning experience in the Malaysian classroom

Mai Neo

Developing a learning object metadata application profile based

on LOM suitable for the Australian higher education context ..... 191-208

Shirley Agostinho, Sue Bennett, Lori Lockyer and Barry Harper

Automated formative feedback and summative assessment using

individualised spreadsheet assignments

Paul Blayney and Mark Freeman

Exploring the use of blogs as learning spaces in the higher

education sector

Jeremy B Williams and Joanne Jacobs

Visualising learning goals with the Quail Model

Luca Botturi

C 2004 All rights reserved. No part of this journal may be reprinted or reproduced without permission from the publishers. The Australasian Journal of Educational Technology is a refereed research journal published three times per year jointly by the Australasian Society for Computers in Learning in Tertiary Education and the Australian Society for Educational Technology. Members of ASET, ASCILITE and ISPI (Vic) receive AJET as a part of their membership benefits. 
For details on submission of manuscripts, subscriptions and access to the AJET online archives, please see http:/ / www.ascilite.org.au/ajet/

For review inquiries, contact the Editor, Associate Professor Catherine

McLoughlin, School of Education (ACT), Australian Catholic University, PO Box

256, Dickson ACT 2602, Australia. Email: C.McLoughlin@signadou.acu.edu.au, Tel:

+61 262091100 Fax +61 26209 1185. For production matters and subscriptions

contact the Production Editor and Business Manager, Dr Roger Atkinson, 5/ 202

Coode Street, Como WA 6152, Australia. Email: rjatkinson@bigpond.com, Tel: +61 8 93671133

AJET is managed by an Editorial Board nominated by ASCILITE and ASET. The 2004 Editorial Board comprises:

Catherine McLoughlin (Editor), Australian Catholic University

Roger Atkinson (Production Editor)

Trish Andrews, University of Queensland

Carolyn Dowling, Australian Catholic University

Mike Keppell, Hong Kong Institute of Education

Lori Lockyer, University of Wollongong

Mary Jane Mahony, University of Sydney

Elizabeth Stacey, Deakin University

\begin{tabular}{c|c}
\hline $\begin{array}{c}\text { Australasian Society for Computers } \\
\text { in Learning in Tertiary Education }\end{array}$ & Australian Society for \\
Educational Technology
\end{tabular}

http://www aset.orgogy

Copyright in individual articles contained in AJET is vested in each of the authors in respect of his or her contributions. Copyright in AJET is vested in ASET (1985-

86), AJET Publications (1987-1996), and ASET and ASCILITE (from 1997).

Desktop publishing and HTML by Roger Atkinson. Printed and bound by Pilpel

Print, Beaufort St, Perth WA 6000, Australia.

Supporting Societies

Supporting societies obtain bulk supplies of printed copies of AJET at the same cost as applicable for ASCILITE and ASET members, and access to AJET online articles during the period of restricted access for each issue. Inquiries about supporting society status may be directed to the Production Editor.

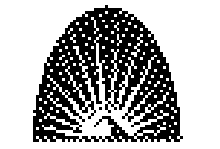

ISPI Melbourne Chapter

IFTIRHATIOHAI

Soc IITY rop

Pretophatcr

IHPROFTHYF 


\section{Editorial: AJET Author Survey}

On 24 May 2004 I despatched an email survey questionnaire to all authors of articles in AJET Volumes 13-19 and 20(1), 1997-2004. During this period AJET published 121 articles (excluding editorials) written by 231 persons. After eliminating those for whom a correct email address could not be found by simple searches, the number remaining was 190. Until closing on 4 June, I received 40 responses $(n=190$, response rate $21 \%)$. No reminder or follow up messages were sent. To promote ease of reading and encourage responses, I restricted survey length and explanation to a minimum, used only body of message plain text (the current flood of email viruses is a disincentive for sending attached files), and omitted explanations of terms such as "pdf", "html", "online discussion facility", etc, because for AJET authors such explanations were likely to be redundant. Being very brief, the survey contained only 7 questions, labelled and sequenced A to $\mathrm{H}$.

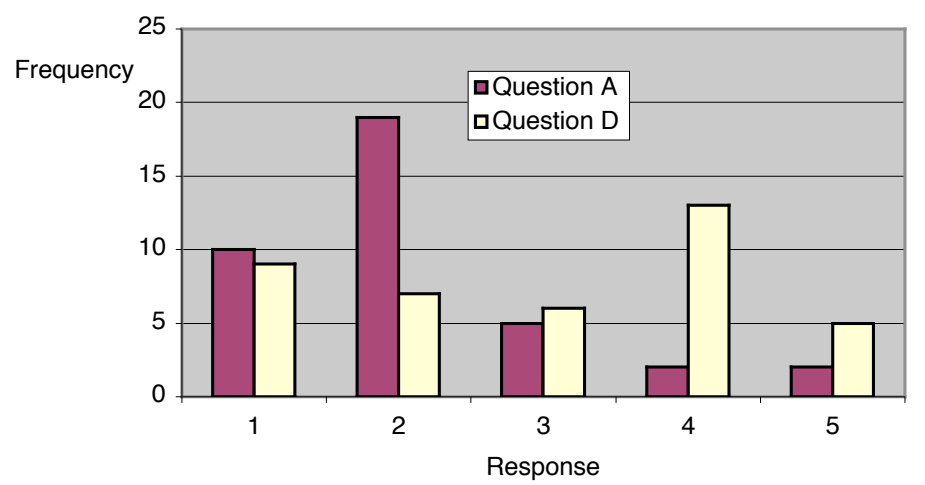

Figure 1: Responses for Questions A ( $\mathrm{n}=38)$ and $\mathrm{D}(\mathrm{n}=40)$

A. Comparing the pdf and html formats, what is your preference for online publication of journal or conference articles you have written? For online publishing of my articles I:

1. strongly prefer pd

2. prefer pdf

3. am neutral, no preference for one over the other

4. prefer html

5. strongly prefer html

D. What is your preferred file format for screen reading of research articles? (preferred file format for printer dump is covered in the next question):

1. strongly prefer pdf

2. prefer pdf

. am neutral, no preference for one over the other

4. prefer html

5. strongly prefer html 
The main aim for the survey was to obtain information from AJET authors on their preferences for AJET website file formats. Figure 1 (above) indicates that authors have a significant preference for pdf over html, for publishing their work (Question A), although a sizeable proportion prefer html for screen reading (Question D).

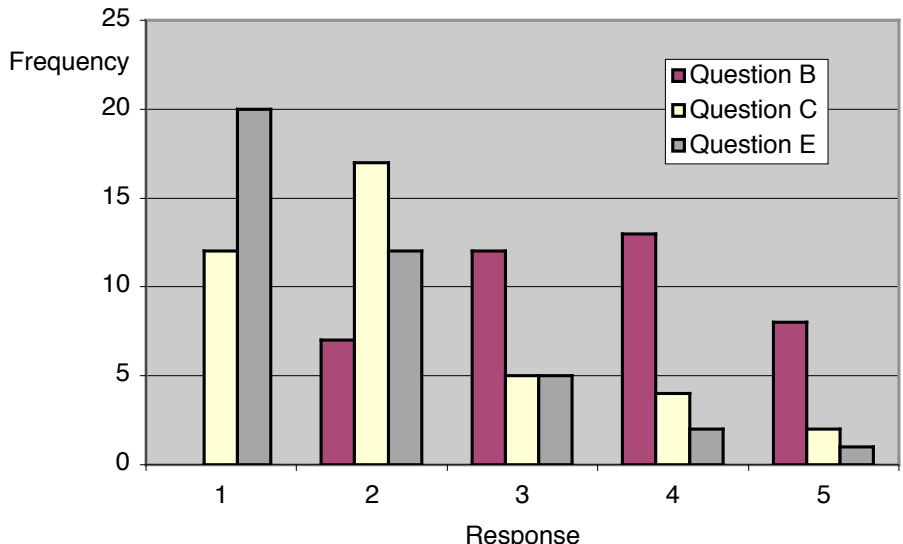

Figure 2: Responses for Questions B $(n=40), C(n=40)$ and E $(n=40)$

B. How would you describe your access to research articles in journals and proceedings? (the question of whether to convert screen access into printer dump is covered in C. below). My research article access is:

1. nearly all hard copy

2. mostly hard copy

3. about equal hard copy and on screen

4. mostly on screen

5. nearly all on screen

C. What is your approach to the reading of research journals and proceedings available to you only via screen delivery (ie you do not get a printed copy either via personal subscription or via your institutional library)? For this class of

delivery my reading is:

1. nearly all from printer dump

2. mostly from printer dump

3. about equal

4. mostly on screen

5. nearly all on screen

E. What is your preferred file format for reading of screen delivered research articles that you have dumped to printer?

1. strongly prefer pdf

2. prefer pdf

3. am neutral, no preference for one over the other

4. prefer html

5. strongly prefer html 
Figure 2 (above) suggests that authors' access to research articles is mainly via the screen (Question B), although their reading of research articles is mainly via printer dumps for hardcopy (Question C). Consistent with this pattern, authors strongly prefer pdf for printer dumping. This is likely to be related to features such as better positioning of tables and diagrams, and the retention of original pagination, when printing from pdf compared with printing from html files, although this survey did not inquire into specific reasons for preferences.

Question F (Figure 3, below) showed strong support from authors for "free to the Internet" publishing as a positive influence upon the academic value of a journal. However, authors seemed reluctant to press that view upon AJET (Question F, Figure 3), most preferring no change in policy.

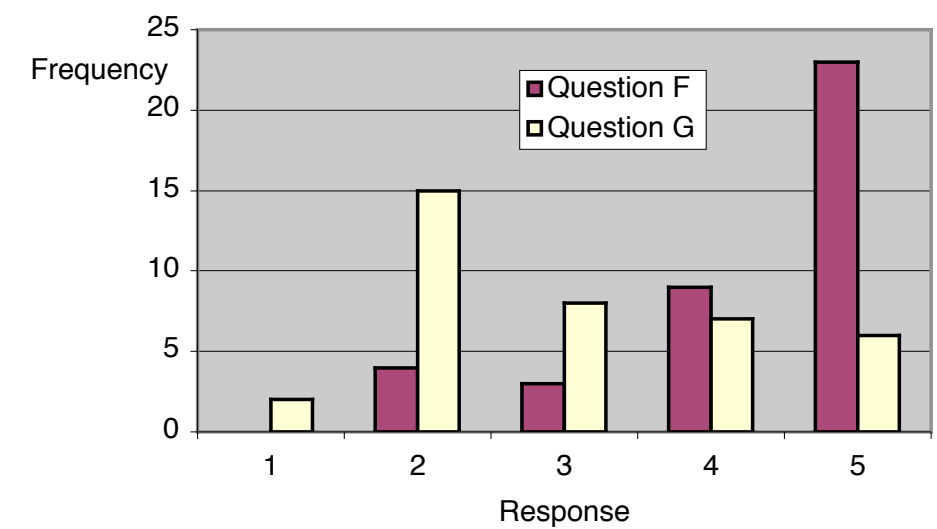

Figure 3: Responses for Questions F ( $n=39)$ and $G(n=38)$

F. What is your rating of the contribution of "free to the Internet" to the academic value and influence of a journal? Free to the Internet publishing is:

1. a very negative influence or disadvantage

2. some disadvantage

3. no advantage or disadvantage

4. a modest benefit
5. a highly significant benefit

G. What is your attitude towards AJET's current access control to the online

version (password or domain name exemption required to access articles during the first three months after the date of publication; after that, free to the Internet)? My attitude is:

1. Current policy strongly supported; increase the period of restricted access.

. Current policy supported; maintain the period of restricted access as it is.

3. Neutral; no strong view for or against a change to current policy.

4. Some preference for a more relaxed policy; shorten access restrictions.

5. Strong preference for eliminating all access restrictions and going wholly "free to the Internet". 
Question H (Figure 4, below) suggests that authors are cautious about introducing an online discussion facility as a new feature for AJET. As the question indicated, we do not have any specific design in mind, and that may have contributed to author cautiousness and diversity of responses.

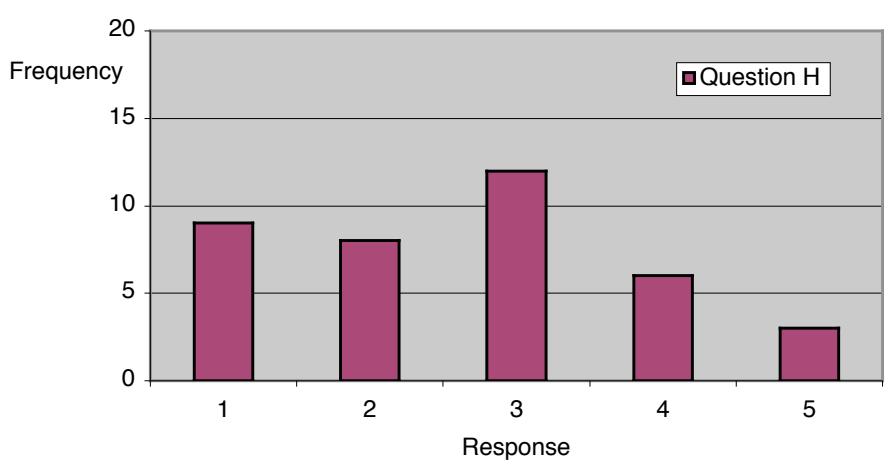

Figure 4: Responses for Question $\mathrm{H}$

$H$. What is your likely level of interest in an online discussion facility associated with each article or groups of articles published in AJET? (We do not have any specific design or set of features in mind, we are seeking only a preliminary

specific design or set of features in mind, we are seeking only a pre
needs analysis and indicators on directions, if any, to explore):

1. Negative, little interest (eg. I am unlikely to support it as an author or reader, not a useful commitment of scarce time, prefer other non-journal avenues for

2. Some interest (eg. a possibility of my support for it, a chance that it could be a useful minor feature, though few journals use an associated discussion facility)

3. A neutral level of interest (eg. could have possibilities if developed appropriately, worth asking for more details).

4. Cautiously positive (I could support a demonstration or trial or pilot implementation, interested in obtaining more details).

5. High interest (eg. I perceive a novel enhancement for online academic publishing, keen to participate as author and reader in a demonstration or trial or pilot implementation for AJET, see possibilities for doing better than other journals that have experimented with discussion facilities, interested in contributing to the design and conduct of a discussion facility).

Authors' freestyle comments on Question $\mathrm{H}$ highlight some of the reasons for the diversity of responses:

- ...for me, these activities are not useful. I go to conferences to get a range of opinions. (Carmel McNaught, Chinese University of Hong Kong)

- I have written for such a journal ... it worked because the discussion was tightly controlled (1-2 days discussion per paper) using an email discussion list, archived to web, just like an online conference. For AJET, the password control would work against this. (Kieran Lim, Deakin Uni)

- ...the reality has been Ihave found it very difficult to keep up with [online discussions of journal articles]. More and more of these are being put up. I 
would think you need to consider very carefully if the effort in getting this up for AJET and keeping it going will be worthwhile. Maybe something more limited - just once a year - could be a way to test the waters. (Rowan Hollingworth, University of New England)

- ... a good idea, but I suspect you might not get enough contributions to make it worth while for individual articles. (Joe Luca, Edith Cowan Uni)

Having conducted the survey, what do we do next? Notwithstanding the lack of a readily findable email address for $18 \%$ of the authors in Vols 13-20(1), and a low response rate of $21 \%$ from the remainder, the survey results are probably sufficiently reliable to be valuable inputs into reviews of AJET's publishing policies.

Producing and web mounting a pdf version of AJET seems to be warranted from the author feedback. Freestyle comments from authors included:

- I prefer html for viewing but pdf for printing and archival purposes. I prefer simultaneous online publication in both formats. (Kieran Lim, Deakin Uni)

- Printing HTML is a pain and unreliable so PDF better. But PDF not good for on screen [reading]. ...depends on the HTML.... [get] rid of the bad habits in HTML of trying to dictate screen layout and size to the reader... get rid of sidebars, all width specs... (Steve Draper, University of Glasgow)

- [screen reading] prefer html because font is clearer than reading pdf on screen ... [screen delivered... dumped to printer] prefer pdf - easier to print - retains format (Mary Rice, Deakin University)

We will investigate the main difficulties with the addition of a pdf version of AJET and proceed if feasible. Problems include the negotiation of additional disk space from AJET's site provider, NetSpot (2004), and our A5 page format which is not optimal for A4 printing. The disk space question arises because it would seem best to offer both html and pdf. Some journals offer both formats, although it is noteworthy that one publication similar to AJET, Educational Technology $\mathcal{E}$ Society (IFETS, 2004), changed recently from html and pdf to pdf only.

Author perspectives need to be combined with others, including Society members, readers, librarians and the scholarly publishing industry.

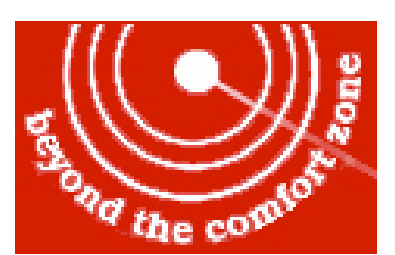

\section{ASCILITE 2004}

The University of Western Australia

5-8 December 2004

http://www.ascilite.org.au/conferences/perth04/ 
Gathering these additional perspectives will take some time, and further reviewing will be at a modest pace, given that we are under pressure on other matters. AJET received 47 submissions during Jan-June 2004, compared with 25 for the same period in 2003, and 61 for the whole of 2003. At the time of placing AJET 20(2) with our printing company, AJET 20(3) is already over $80 \%$ filled and we may have to make difficult inquiries and decisions on the question of whether our Societies can afford a 'bonus' fourth issue during 2004. However, coping with these tasks is made easier by some very kind freestyle comments about our work made by survey respondents, including:

- [rating of the contribution of "free to the Internet"] real benefit - that is why I chose AJET for my article (Robyn Mason, UK Open University)

- AJET is a well-known and respected journal in Canada... [Richard Schwier, University of Saskatchewan)

- It is a great journal thanks for all your work on it. (Mark Freeman, U Sydney)

- AJET is doing well as international reputable Journal. Keep up the good work. (Myint Swe Khine, Nanyang Technological University)

\section{Roger Atkinson}

AJET Production Editor

\section{Acknowledgments}

Draft versions of the survey were improved by helpful feedback from three researchers and practitioners who had not published in AJET Vols 13-20(1): Rod Kevill, Curtin University of Technology; Barnard Clarkson, Edith Cowan University; and Lesley Richardson, University of Southern Queensland. The unofficial prize for fastest response was awarded to Rob Phillips, Murdoch University: emailed to on 24 May 2004 10:19:49 +0800, response dated 24 May University: emailed to on 24 May 2004 10:19:49 +0800, response dated 24 May

\section{References}

AACE (Association for the Advancement of Computing in Education) (2004). AACE Publications. http:/ / www.aace.org/pubs/

IFETS (International Forum of Educational Technology and Society) (2004). Educational Technology \& Society. http:/ / ifets.ieee.org/periodical/

NetSpot (2004). http: / / www.netspot.com.au/

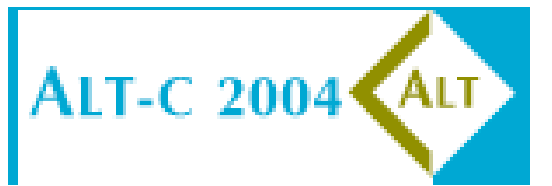

ALT-C 2004: Blue skies and pragmatism learning technologies for the next decade

http://www.alt.ac.uk/altc2004/

11th International Conference of the Association for Learning Technology, University of Exeter, England, 14-16 September 2004 